\title{
Hunting the axolotl
}

\author{
Citation for published version (APA):
}

Sluijter, M. E. (1998). Hunting the axolotl: Lecture to commemorate the farewell of Prof. dr. M.E. Sluijter. Universiteit Maastricht. https://doi.org/10.26481/spe.19981127ms

\section{Document status and date:}

Published: 27/11/1998

DOI:

10.26481/spe.19981127ms

Document Version:

Publisher's PDF, also known as Version of record

\section{Please check the document version of this publication:}

- A submitted manuscript is the version of the article upon submission and before peer-review. There can be important differences between the submitted version and the official published version of record.

People interested in the research are advised to contact the author for the final version of the publication, or visit the DOI to the publisher's website.

- The final author version and the galley proof are versions of the publication after peer review.

- The final published version features the final layout of the paper including the volume, issue and page numbers.

Link to publication

\footnotetext{
General rights rights.

- You may freely distribute the URL identifying the publication in the public portal. please follow below link for the End User Agreement:

www.umlib.nl/taverne-license

Take down policy

If you believe that this document breaches copyright please contact us at:

repository@maastrichtuniversity.nl

providing details and we will investigate your claim.
}

Copyright and moral rights for the publications made accessible in the public portal are retained by the authors and/or other copyright owners and it is a condition of accessing publications that users recognise and abide by the legal requirements associated with these

- Users may download and print one copy of any publication from the public portal for the purpose of private study or research.

- You may not further distribute the material or use it for any profit-making activity or commercial gain

If the publication is distributed under the terms of Article $25 \mathrm{fa}$ of the Dutch Copyright Act, indicated by the "Taverne" license above, 


\section{HUNTING THE AXOLOTL}

Prof. dr. M.E. Sluijter

Lecture to commemorate the farewell as Professor in invasive methods of treatment of chronic pail from Maastricht University

Noventber 27, 1998 
Mijnheer de Rector.

Ladies and Gentlemen,

\section{1}

\section{Introduction}

Once upon a time there was a weekly opinion journal in the Netherlands which was called "de Groene Amsterdammer". As opinion journals go it does not exist anymore, but there was a lot of wisdom in it. Every week there was a column on the back page. The column treated various seemingly trivial subjects, but it did so in a humorous and moralising fashion - the last adjective is not so surprising since it was a Dutch journal. Invariably the subject for the next week was announced in the last sentence, and invariably that subject was the axolotl. This was sad news for pessimists, since they had to worry for a week what the next column would be all about and it was good for the optimists since they had their. own perception of what this little animal looked like and since therefore they had the certainty of knowing next week's subject.

Axolotls in this sense are concepts which we have formed for ourselves. Pertinent to this day's subject an axolotl may be our concept of the underlying mechanism of chronic pain, of the way it should be treated or of the research which is now in order. Since in the medical scientific world the survival rate for pessimists is minimal this community is full of optimists with very clear ideas on the shape and character of the true axolotl. They each create their own little animal, they put it on their desk, they foster and they admire it. Unfortunately axolotls donot have a very nice character. Once they have been created they tend to have a personality of their own and they are resistant to change. In order to prevent change they try to influence us from outside. In other words: once we have cleverly conceived a view on a mechanism or on a modality of treatment we have to overcome considerable resistance to change that view and 
we experience this resistance as an outside force. Overcoming this resistance stands in the way of progress and therefore axolotls have to be hunted and chased away constantly. This hurts, because naturally we have sympathy for our own creation. Nevertheless we must never leave them at rest, because if we do we are captives of our own ideas. So let us go over the field of the treatment of pain and let us see if we find any stuffy old axolotls that should have been chased a long time ago.

The axolotl only thrives on the soil of complexity and of different interpretations of phenomena and of mechanisms. There is no place for axolotls in astronomy or in physics. One such environment of extreme complexity is chronic pain. Not the concept of chronic pain which we used to foster in the past. In the old view pain was no more than a symptom of disease, resulting from a stimulus which originated from the periphery and which reached the brain in predictable intensity causing a predictable and proportionate degree of suffering. Chronic pain in that concept was the result of failure of medicine to take away the cause and when medication was of no avail suffering had to be accepted. In our litthe country this went well with our Calvinistic tradition and whoever happened to disagree with that tradition had the misfortune of having to accept the suffering anyway. It is worth remembering that the era of this concept is not as far behind us than we may think. When I instituted my first consultation hour for chronic pain in 1973 there was vocal objection from part of the medical staff, claiming that a consultation for the treatment of symptoms might do harm to the reputation of the hospital.

\section{2} The gate control theory

It is against this background that we have to appreciate the effects of the gate control theory by Melzack and Wall and its less 
well vocalised precursors. Never mind the details of that theory, which may or may not be exactly right. Its importance goes far beyond trivial discussions. What the theory did was revealing the complexity of chronic pain and thereby giving birth to a multitude of axolotls. I know that many of you are familiar with the theory but for the sake of clarity I need to explain the principle.

Stimuli from the periphery travel towards the spinal cord in two distinct fibre systems. In the first system the fibres have a large diameter, because they are covered by a myelin sheath. Conduction in these fibres is fast and the localisation of the originating stimulus is sharp. In the second system the fibres are not covered by myelin and their diameter is therefore small. Conduction is slow and the localisation of the originating stimulus is imprecise. These fibres play an important role in the mechanism of chronic pain. You can easily notice the difference between the two systems. Next time you cut your finger pay close attention. You will instantly feel exactly where you cut it but it will not really give you a sensation which we define as pain and the sensation will be of short duration. This is the effect of the large fibre system. After some minutes you will have a completely different sensation. Now you will feel a duil, ongoing agonising pain but you will have difficulty in localising it. This is where the small fibre system comes in.

The gate control theory merely says that the transmission of stimuli on entering the spinal cord is not automatic. First, there is the interaction between the two fibre systems. Stimulation of the large fibre system tends to inhibit the transmission to the next station. Stimulation of the small fibre system facilitates transmission. In other words: The large fibre system closes the gate, the small fibre system opens it. Secondly, there is an important influence of information which comes from the brain through the so-called descending tracts. This is where the influence of psychological factors come in. 
This influence is so powerful that an acute trauma may be painless when there is an intense psychological upset at the same time. There is therefore a process of weighing and filtering information once it arrives at the spinal cord and this process is probably repeated several times as the stimulus travels up to the brain. Why is this so important? Because this implies that there is a dissociation between the original stimulus and the final emotional experience which we define as pain. This dissociation is influenced by psychological factors on one hand and by the nature of the incoming stimuli on the other. It is not surprising that this spectacular deviation from earlier views gave rise to a multitude of axolotls.

That was not the only effect of the gate control theory. There was also a profound influence on the treatment of chronic pain. Before the gate control theory the invasive treatment of chronic pain was invariably destructive in nature. Nerves or nerve structures were either cut with a knife or they were destroyed by injecting neurolytic substances or by applying heat or cold. After the gate control theory the emphasis was on electrical stimulation of the large fibre system in order to artificially augment the closing effect on the gate. Destructive procedures became outmoded with the debated exception of radiofrequency, since it was thought that radiofrequency could provide a partial destruction leaving the gate closing effect of the large fibre system intact.

\section{3}

\section{Psychological factors in pain}

In terms of non-invasive treatment there was predictably an emphasis on psychological factors. Many psychologists developed an axolotl where the role of nociception is virtually non-existent. In their view "Pain is in the mind" and nociception is at best of temporary importance. Accordingly any form of chronic pain which exists for a longer period of time is governed by psychological factors 
exclusively. I bring this up because this axolotl gained considerable popularity and because this view also pervaded the public opinion to some extent. The question at stake here is: Are we justified to do invasive procedures in the treatment of chronic pain?

This psychological axolotl is however not tenable as a general rule. First - although pain is of course always ultimately in the mind there is now abundant evidence that invasive procedures do have an effect in a proportion of chronic pain patients. The effects of SCS are well documented and the effects of certain RF procedures are proven in double blind studies. Also the concept that the role of nociception necessarily fades as time goes by cannot be upheld. Just to name an example: In a series of patients who were treated for a socalled "whiplash syndrome" we found that these patients could respond well to RF treatment even when their trauma was more then ten years ago. There is in conclusion an effect of invasive procedures and there is no simple relationship between the duration of pain and the importance of psycholoical factors.

This is not to say that psychological factors are irrelevant in chronic pain. Their importance is well recognised and indeed it is customary to perform psychological tests before instituting the more complicated invasive procedures involving implants. This however is not an easy task. Let me give you two contrasting examples to illustrate the difficulty. The first example is a 68-year old woman who consulted me for a dull, constant pain in the upper jaw. She made a well composed, adequate impression and she certainly did not strike me as being depressed. When I asked her when the pain had started she gave me the exact date around twenty years ago. This of course rings a bell, and when I probed further it turned out that this was the day of her mother's funeral. On that day she had seen her younger sister again with whom she had had bitter arguments for many years. The younger sister as usual could not control herself 
for the occasion and she made a very rude and insulting remark. It was, my patient said, "as if somebody was hitting me in the face". It was on that very moment that the pain had started. Of course one does not have to be a psychologist to see the connection and in this case a simple explanation of the likely mechanism was all that was needed to relieve the pain.

But life is not always so simple as the next story illustrates. In comes a man in his late forties, heavily overweight, walking with a cane and loudly lamenting about his fate even before the door of the consulting room opened. If I could not do something about his pain he volunteered to be ready for suicide. Even with plugs in my ears and dark sunglasses on I could have made a diagnosis of heavy psychological involvement. He would definitely not have passed any test to justify complicated invasive treatment. The only argument for giving him the benefit of the doubt was the fact that the unbearable pain in his loin had started following a complication of renal surgery. This patient underwent a diagnostic segmental nerve block, predictably orchestrated with further lamentations and without a trace of cooperation. But the result of the block was positive and the dorsal root ganglion procedure which followed a week later took his pain away completely.

This story shows you how difficult it is to weigh the impact of psychological factors. Of course these were just casuistics, but studies of groups of patients donot provide complete clarity either. It is true that chronic pain sufferers score higher for depression, but it is also true that following successful treatment of any kind a pathologic psychological profile tends to normalise. There are no tests available which conclusively answer the question which comes first: the chicken or the egg. Unfortunately opposing axolotls in this field will be with us for some time to come. 
The lesson we have to learn from this is that in the daily patientdoctor confrontation a lot depends for the time being on experience and on personal judgement. The day has yet to come that a pain patient can be equated to a summation of test results and since every human being is unique that is maybe just as well. In these days of interest in what is technically possible such as electronic hospital records and automated letters to the general practitioner let us not forget the importance of simply chatting with your patient. Soccer is convenient, especially on the numerous occasions when Ajax has won and there is conveniently always something to complain about our climate. The response will quickly give you a wealth of information which goes far beyond the identification of the patient's favourite soccer team.

But after this diversion let us get back to our little animals. As said, the gate control theory provided ample soil for their multiplication. Each discipline had his own view of what the chronic pain patient was like. This was recognised and action was taken by the formation of multidisciplinary groups. These groups have in their turn been going through a learning curve. The true aim of a multidisciplinary group must be not to sit around the table each with his own axolotl in front of him, but to merge all the different axolotls into one conjoint animal. It is this continuous movement towards convergence which $I$ have strongly felt during my presence at this university and I wish to compliment both the coordinator and all the disciplines which are involved in the pain group. It was a joyful experience.

\footnotetext{
$\triangle$ Electrical stimulation

4 As said, the phenomenon of axolotls is not confined to the mechanisms which underly chronic pain. Once the mechanism is understood and the diagnosis has been made, treatment must be
} 
instituted. Here again the soil for axolotls is fertile since there is complexity and since there is ample room for opposing views. In the old days there was understandably an emphasis on destruction of nerves or nervous structures. Destruction was sought of the Gasserian ganglion for the treatment of trigeminal neuralgia, there was exairesis of peripheral nerves such as the maxillary and supraorbital nerves and nerves and nerve roots were cut for a variety of pain syndromes. The result of most of these procedures was almost invariably disappointing and not exceptionally the pain became worse instead of better. It is in fact amazing in retrospect that this approach could survive for such a long period. It is a good example of the power of an axolotl once it has been created.

Following the advent of the gate control theory the emphasis was on non-destructive methods and the method of SCS was developed, where an electrode is introduced into the epidural space close to the spinal cord. The electrode is then connected to a stimulator and the whole system is implanted. Once the system functions stimulation is indeed totally harmless as far as we know. For that reason the axolotl of SCS is a harmless little animal. What is conveniently forgotten is that the method is not without its complications. Infection may occur, the catheter may be displaced and stop functioning properly and there have even been instances of damage to the spinal cord. Put in other words: the attractive looks of the axolotl of SCS are based on the label of the method rather than on the product. There are additional disadvantages. When using SCS we seek a solution for a pain problem which is an implanted device. This needs constant attention by the patient, who each time will focus on his pain problem. From the doctor's point of view SCS is comparable to marriage without the option of divorce. The patient will blame every somatic discomfort on the implanted system and will call the doctor's office without delay. 
This is all very well as long as we donot have something better. SCS is a blessing as an instrument to relieve pain in a group of patients to whom we have nothing else to offer. The point I wish to make is that we should not let the axolotl have power over us, telling us that this is the ultimate solution which will be with us forever because it is harmless. We should constantly be asking ourselves whether or not we should really be implanting ever more sophisticated implants into patients who are often of a young age to solve their pain problem.

\section{5}

\section{Radiofrequency}

What about the destructive procedures? The age of culting nerves with a knife is history now - or at least it should be. What about RF? RF is a method in which an electrode is positioned close to a target structure in the body. When RF is applied to the electrode, heat is generated around the electrode tip. There are various forms of RF depending on the purpose which is intended. First, there are applications where the aim is destruction of tissue. The most shining example of this is the thermal destruction of tumour metastases. Utilising an ingenious technique where the centre of the lesion is cooled to prevent gas formation large metastatic tumours can be destroyed.

The application of $\mathrm{RF}$ for the treatment of chronic pain is totally different. The electrode is positioned close to a nerve or to a nervous structure. The heat partially destroys the target structure and this stops the conduction of the stimuli which cause the pain. The principle of this method, which was introduced for spinal pain by Shealy in 1972 seemed so obvious that nobody has ever taken the trouble to question the legitimacy of this axolotl. 
Still, when we take a closer look, the relationship between the formation of heat on one hand and the clinical effect on the other is not so clear. Let us focus on the average clinical course following a RF lesion adjacent to the dorsal root ganglion. What happens first is a period of postprocedural pain and discomfort. This period may last for several weeks. During this period there may be numbness in the treated dermatome. This numbness quickly recovers and six weeks after the procedure the sensory qualities are back to normal. If there is a beneficial clinical effect this commonly sets in 3 to 4 weeks following the procedure and it then keeps up for at least six months following the procedure according to most studies. There is then a recurrence of pain in a modest proportion of patients over the second half year, but in many cases the beneficial effect remains intact over this period and in fact much longer than that.

This on second thought is very odd. Clearly there is partial destruction of the large fibre system but this recovers quickly at a time when the clinical effect sets in. This partial destruction must therefore be a phenomenon which is not related to pain relief. If RF lesions really work through destruction by heat we should therefore focus on the small fibre system. But here we are confronted with the same phenomenon. If a nerve cell is partially damaged, it tends to regenerate within weeks or at most within a couple of months. Partial damage would therefore not explain a long-term clinical effect. If the destruction of the small fibre system is complete, and if this indeed causes the long lasting clinical effect, then an RF lesion must be superselective. It should at the same time cause partial, temporary damage to the cells of the large fibre system and complete destruction of the cells of the small fibre system. There is so far no evidence whatsoever that this is the case.

The conclusion must sadly be that for over twenty years we have overlooked the fact that the time course of the clinical effect of an 
RF lesion contradicts the effect of destruction by heat. It simply cannot be so. We have failed to chase a trusted but old and stuffy axolot. There must be another effect which we donot know, and this is now confirmed by new developments. The conclusion that the effect of RF lesions is not due to destruction by heat has far reaching consequences. If destruction is irrelevant, why heat at all? Indeed, this has prompted us to develop a new technique in which RF is not applied continuously but in a pulsed fashion. In this way the production of heat is minimal and whatever heat is produced is quickly eliminated during the silent phase of the duty cycle. Still the tissue which surrounds the electrode tip is exposed to an electric field which is of the same order of magnitude as the field which is operative while making a heat lesion.

So far it looks like the effect of such a procedure is indistinguishable from the effect of the destructive heat lesion. In terms of ultimate clinical effect this still has to be proven in double blind studies, but a lot is to be learned from simple observation. The pulsed RF method is ideally suitable for this, since the method is painless. This is because there is no heat formation around the electrode tip and because the frequency of $500.000 \mathrm{~Hz}$ during the active phase is far outside the physiological range, so that neurons in the vicinity of the electrode donot depolarise. In a cooperative patient it is therefore possible to do the whole procedure without any form of sedation and without injecting any local anesthetic solution.

These are ideal circumstances to observe the immediate effect. This may not be so easy to interpret in complicated types of pain such as back-and neck pain but it is quite easy in facial pain or in headache. As an example let me tell you what we observed in a patient with continuous, 24 hours per day, ongoing headache in the L frontal region. At regular intervals the pain would get worse and culminate into an attack with all the characteristics of migraine. He had un- 
dergone a number of RF procedures but this had not relieved his pain. A placebo effect was therefore very unlikely. This patient became instantly free of pain following a pulsed RF procedure of the $\mathrm{C} 1$ nerve. A similar time relationship we have observed following a percutaneous cordotomy and following a procedure of the Gasserian ganglion for trigeminal neuralgia. This immediate effect is not a constant phenomenon and it is of short duration, ranging from 6 hours to several days.

It therefore looks like the action of RF is through the electric field rather than through destruction by heat. There is an immediate "stunning" effect which may or may not be some form of minidestruction. Next there is a second effect which becomes operative at a later stage and which is of long duration. The two phases seem to be unrelated. "Sturning" is not necessarily followed by long term pain relief and vice versa. These developments are so recent that we donot know yet what the nature of this second effect is. Presumably it is an effect on the properties of the neuron, in which case the effect of RF would be true neuromodulation in stead of destruction. This would be a truly revolutionary development. So far it has been thought that neural conduction could be influenced in two ways: chronic stimulation of the large fibre system or destruction. The present findings suggest not only that a change of properties of the neuron may play a role but also that these changes may be induced by applying an otherwise harmless electric field. This potentially opens up a perspective of new methods of treating pain.

Since RF lesions already had the advantage of lacking the complications of implant devices and of being performed with small diameter instrumentation it now becomes a very attractive technique. It also becomes a technique which may easily be misused under the pretense that it does no harm anyway. This is undesirable and even potentially dangerous, since any invasive 
procedure is subject to a risk of complications, however small. The indication to do an invasive procedure for the treatment of pain should be based on the diagnosis.

\section{Research}

A final axolotII would like to discuss with you is the holy altar of the double blind studies. It has come to the stage nowadays that many respectable journals donot accept articles unless they describe the outcome of a double blind study. Not that double blind studies are always feasible. If the procedure involves amputating a leg it is of course hard to write a suitable protocol but since the introduction of an RF electrode is relatively harmless the demand is mandatory in RF research. Let us have a look at the facts. I think it is fair to state that there are two types of double blind studies. In the first type you try to prove or disprove a relationship between two phenomena which is not obvious beforehand. Let me give you an example. While preparing this lecture I had the misfortune of consuming a ready made meatball that I bought in a supermarket. It tasted like synthetic rubber with some soya sauce added. There is a distinct possibility that regular consumption of such products will decrease life expectancy but this need not necessarily be so.To prove or disprove this you would have to do a double blind study comparing these synthetic balls to home made meat balls. Certainly the result could be marked as scientific progress and in this case one with a marked practical consequence as well.

In the second type of double blind study things are different. During my stay at this university I have proudly participated in a number of double blind studies regarding the effect of RF lesions. It was high time to conduct these studies, for too long the effect of these procedures had not been properly documented. What did it bring us? It confirmed what we already knew from long standing 
experience. A good example is the treatment of cervicogenic headache. We have been treating that condition for almost twenty years now with RF lesions in the cervical region and it was well known to us that this was effective in a large percentage of patients. A prospective pilot study at our department strongly confirmed this. Now a double blind study has been undertaken. Is this a good thing to do? The answer is yes as long as we realise that its sole purpose is not to find new information but to convince the sceptics who argue that it might all be a placebo effect.

To those of you who are unfamiliar with the meaning of a placebo effect let me give an example. We Europeans know that when you drink too much morning coffee your heart may give an extra beat. But this is not an effect which is universally known. On my frequent and pleasant travels to USA I often find a coffee machine in my hotel room. So in the morning I activate the machine and out comes a hot brownish fluid. On tasting it it is easily recognised that this has nothing to do with coffee, that indeed there cannot possibly be a trace of caffein in the fluid. Still Americans pretend that they too get cardiac arrhythmias from their morning brew and even go to the extent of asking for decaffeinated fluid. Why is this? Because it says on the machine with big letters: "Mr Coffee". This then is a placebo effect.

In this context the double blind study on cervicogenic headache is like comparing coffee to coloured American tap water. The outcome is quite obvious beforehand. If the result would indicate that there is indeed caffein in the fluid there is something wrong with the setup of the study. No scientific progress is to be expected. For RF there is an additional problem. Spinal pain is complex and to have a good result from RF treatment various types of treatment are often needed. To stick to our example: it is not just a matter of the coffee, it is the effect of the complete breakfast which is rele- 
vant. With double blind studies one can only look at one ingredient. It is either the coffee or the eggs.

Still double blind studies require time, energy and financial resources. It is worth while to pause a moment and contemplate what the pursuance of double blind studies has stopped us from doing over these nine years. Double blind studies consume so much time and energy that still today we donot know what exactly the time course and intensity are of sensory changes following a RF lesion, nor do we know the long term time course of the clinical effect of complete RF treatment as a whole for a certain pain syndrome. It is all very well to prove that a medial branch RF block is clinically effective as compared to placebo but we have to realise that this is not what the society and the health insurers and other medical disciplines are asking us. They ask whether or not RF treatment is useful and cost effective and whether or not it makes sense to do a referral for a certain pain syndrome.

The message being that double blind studies are useful and necessary but that they should not frustrate progress. The obsessive focussing on this type of study potentially does just that. The axolotl should not be chased but it should be told to shut up a little. Maybe it is time to start a new medical journal which is entirely dedicated to observations and to unproven but well thought through ideas. Ironically the world of pain has to offer a perfect example of what such an idea can mean to society: the gate control theory.

\section{Closing remarks \\ So what is the message of all this? What do I want you to take home?}

Invasive procedures have become indispensable in the armamentarium which we have at our disposal to treat chronic pain. The re- 
sults are steadily improving, there are results of double blind studies, there are results of well designed prospective clinical studies, there is every reason to be content. We write consensus reports on forms of treatment which we hardly understand but the winner is always right and the next working day we continue as usual with our implants and our lesions. And in the distance we hear a Siren softly singing that all is well.

I have tried to convince you in this hour that this Siren is a dangerous woman. All is not well and we should not sit back and watch the axolotls on our desk in peace. We should not sit, we should run. There are ideas to be conceived and there is work to be done. We are at the very beginning and nowhere near the end.

Ladies and Gentlemen, I come to the close of this lecture. This occasion has given me the prerogative to provoke a little, but any good tale has a jester and a devil. I have filled this post for nine years and it was a stimulating - and perhaps a modulating - experience which has given me great pleasure. I consider myself fortunate that I have been offered the opportunity to continue some of this work in the years to come at a more leisurely pace. This necessarily is abroad since it is a Dutch national axolotl that creative thinking stops at the age of 65 . There is nothing dramatic about this. Traveling is my fate anyway for reasons which I fail to understand and I hope to keep close contact with this department.

I now come to the traditional part of expressing my gratitude to many people who have made these last nine years so enjoyable and to those who have been important to me.

I wish to thank the board of the Dutch Pain Foundation which has made my stay at this University possible. I have done the best I 
could. Much has been achieved - not enough as you have heard during this hour.

Professor de Lange, dear Simon, again I express my sincere gratitude for your continued interest and support. I may have entered into your department as a foreign body and you have assimilated me with genuine gracefulness. The fact that there are now chairs for the treatment of pain at other universities should be considered as a feather on your hat. You have shown that this is an asset to a department of anesthesiology.

Dr. van Kleef, dear Maarten, without your contribution over the years we would not by far have been where we are now. Apart from our personal friendship I have fostered our cooperation. May we long continue our sessions at ' $t$ Plenske and please strictly follow the sequence: pain first, then the misfortunes of Feyenoord, and finally the inevitable question: "maar he, hoe is het verder?"

Drs Barendse, van Suylekom and Weber, dear Gerard, Hans en Wim, I put you on purpose in alphabetical order since otherwise I would have difficulty in deciding the sequence. It has been a privilege to work with you - yes, and to smoke with you after lunch, Gerard. I have felt an atmosphere of effortless cooperation. These were good years and thank you so much for that.

Professor Sjaastad, dear Ottar, our professional meeting in Trondheim has rapidly developed into friendship. Thank you so much for being here today, it wrould not have been the same without you. You have sharpened my critical thinking and I hope that we will continue our discussions on headache for a long time to come. And incidentally, you still owe me a lunch in Berlin. 
Professor Racz, dear Gabor, it has come to the stage that we are virtually Siamese twins on the faculty of all those countless meetings. I miss you on the rare occasion when you are not there. We may have our differences of opinion but we share a deep mutual respect and a common goal. Thank you for sharing your warm personality with me on so many occasions.

Dr Mehta, dear Mark, I am more than a little worried about what you are going to say to me tomorrow so please remember that you are my oldest and most trusted friend in the world of pain. Please have mercy and contain yourself.

Professor Cosman and Mr Rittman, dear Eric and Bill, your presence here today is a true honour to me. Our history together dates back for over twenty years now and over these years we have not ceased. our efforts in creative, innovative thinking. Outside the pain work I have deep respect for what the two of you have contributed to mankind. In pain we have operated as a team and may we continue doing so. I need not underline the personal friendship which has grown over the years. You both know.

I also wish to thank all those of you who have literally travelled from all corners of the earth to support me with their presence. I have difficulty in finding words when I want to express what this means to me. I am deeply, deeply grateful to each of you.

Mrs Vlaming, dear Monique, you have grown to be an indispensable certainty in my life. The two available options have been either you or chaos. Thank you so much for having been my umbilical cord to sanity. I am fortunate that through your new function we still have close contact. May it last forever. 
Drs. van Zundert, van Buyten, van Duffel en Vueghs, dear Jan, Jean Pierre, Luc en Peter, my Belgian friends, I have been impressed. There is hope for humanity when some of its members work so hard and with complete disregard for personal gain to the benefit of others. The pain centre that you have created is a shining example of what can be achieved in a peripheral hospital. I am proud to count myself as one of you.

Fleur and Ivo, my children, you have navigated me through a difficult period in my life. Now the waters are quiet and there is the fun and the laughter and the unbreakable bond. You make me play my music in the sun and I am immensely grateful.

Ihave said. 
(9) Prof, dr. M.E Sluijler, 1998

Vormgeving en druk: Datawyse | Universitaire Pers Maastricht 
